\title{
Comparative genomics of the type $\mathrm{Vl}$ secretion systems of Pantoea and Erwinia species reveals the presence of putative effector islands that may be translocated by the VgrG and Hcp proteins
}

Pieter De Maayer ${ }^{1 *}$, Stephanus N Venter ${ }^{1}$, Tim Kamber ${ }^{2}$, Brion Duffy ${ }^{2}$, Teresa A Coutinho ${ }^{1}$ and Theo HM Smits ${ }^{2}$

\begin{abstract}
Background: The Type VI secretion apparatus is assembled by a conserved set of proteins encoded within a distinct locus. The putative effector proteins Hcp and VgrG are also encoded within these loci. We have identified numerous distinct Type VI secretion system (T6SS) loci in the genomes of several ecologically diverse Pantoea and Erwinia species and detected the presence of putative effector islands associated with the hcp and vgrG genes.

Results: Between two and four T6SS loci occur among the Pantoea and Erwinia species. While two of the loci (T6SS-1 and T6SS-2) are well conserved among the various strains, the third (T6SS-3) locus is not universally distributed. Additional orthologous loci are present in Pantoea sp. aB-valens and Erwinia billingiae Eb661. Comparative analysis of the T6SS-1 and T6SS-3 loci showed non-conserved islands associated with the vgrG and $h c p$, and $v g r G$ genes, respectively. These regions had a $\mathrm{G}+\mathrm{C}$ content far lower than the conserved portions of the loci. Many of the proteins encoded within the hcp and vgrG islands carry conserved domains, which suggests they may serve as effector proteins for the T6SS. A number of the proteins also show homology to the C-terminal extensions of evolved VgrG proteins.

Conclusions: Extensive diversity was observed in the number and content of the T6SS loci among the Pantoea and Erwinia species. Genomic islands could be observed within some of T6SS loci, which are associated with the hcp and vgrG proteins and carry putative effector domain proteins. We propose new hypotheses concerning a role for these islands in the acquisition of T6SS effectors and the development of novel evolved VgrG and Hcp proteins.
\end{abstract}

\section{Background}

The Type VI secretion system (T6SS) was first identified in the human pathogens Pseudomonas aeruginosa and Vibrio cholerae and was shown in the latter to function as an injectisome for the delivery of pathogenicity effector proteins into the host cell $[1,2]$. T6SS have since been identified in genome sequences of many Gram negative bacteria, including those of several animal and plant pathogens, but also in symbiotic and free-living bacteria [3]. This has led to the speculation that the T6SS is involved in other non-pathogenic functions including inter-bacterial communication, regulating

\footnotetext{
* Correspondence: pieter.demaayer@fabi.up.ac.za

${ }^{1}$ Forestry and Agricultural Biotechnology Institute, University of Pretoria, South Africa

Full list of author information is available at the end of the article
}

biofilm formation and environmental stress response $[4,5]$. In the animal pathogens Salmonella enterica subsp. enterica serovar Typhimurium and Helicobacter hepaticus mutational analysis indicated that the T6SS suppresses virulence and promotes replication in host cells, thus contributing to long-term colonization [6,7]. In other bacteria, including the animal pathogen Yersinia pestis and the phytopathogen Pectobacterium atrosepticum, this increased proliferation has been hypothesized to result in increased fitness and, subsequently, increased virulence $[8,9]$. The T6SS of the plant symbiont Rhizobium leguminosarum has been linked to host-specificity, where a T6SS deletion mutant of a strain restricted to Trifolium subterraneum (clover cv. Woogenellup) acquired the ability to form nitrogen-fixing nodules on the non-host Pisum sativum (pea) [10]. 
Several authors have identified an antibacterial role for the T6SS. A secreted effector, Tse2, in P. aeruginosa has been shown to have toxic effects on other bacteria [11]. Furthermore, the T6SS effectors Tse 1 and Tse 3 represent lytic enzymes that degrade peptidoglycan in the cell walls of closely related Gram negative bacteria [12]. Similarly, bactericidal functions have been ascribed for T6SSs in V. cholerae [13] and S. enterica [14]. The availability of more genome sequences and more experimental data will facilitate a greater understanding of new and known functions of the T6SS. Several bacteria encode multiple T6SS loci on their genomes. For example, the genomes of $P$. aeruginosa, Y. pestis and Burkholderia pseudomallei encode three, four and six T6SS loci, respectively [3]. These seemingly non-paralogous loci, together with the divergent functions of the T6SS suggests that this secretory system could influence a variety of interactions within a single species, with various hosts, and/or with other bacteria occupying the same niche [3].

While the biological roles of the T6SS in many Gram negative bacteria still need to be elucidated, other aspects of this secretory system, including evolutionary, genetic, structural and regulatory facets are becoming better understood. T6SS loci are generally comprised of 15-25 genes and include a core of 16 conserved proteins, which assemble the T6SS apparatus in the cell membrane [15]. These conserved proteins include IcmF (COG3523) and DotU (COG3455), which have homology to proteins associated with the type IV secretion system and are thought to stabilize the T6SS apparatus in the cytoplasmic membrane [15]. An AAA+ ATPase, ClpV (COG0542) may energize the assembly of the apparatus. Other conserved proteins include the DUF770 (COG3516) and DUF877 (COG3517) proteins, which are predicted to function as chaperones and the COG3521 outer membrane lipoprotein [15]. The outer component of the T6SS apparatus is comprised of two proteins, VgrG (COG3501) and Hcp (COG3157), which have also been identified as secreted effectors of the T6SS [16]. These proteins resemble both structurally and genetically the components of the T4 bacteriophage tail spike, suggesting that the VgrG-Hcp combination forms a similar membrane penetrating structure and are evolutionarily related $[16,17]$. Hcp proteins form hexameric rings that are conceivably stacked to form a tube penetrating the outer membrane through which proteins are transported into the extracellular space [18]. The VgrG protein is postulated to puncture the outer cell membrane to allow extrusion of the Hcp tube and subsequently breach the host cell membrane [16].

VgrG proteins have been demonstrated to be secreted by the T6SS and are themselves required for the secretion of other effector proteins, such as the Tse3 effector in $P$. aeruginosa [19]. However, a VgrG protein in this organism has been shown to be secreted in a T6SS-independent manner [19]. This indicates that the VgrG proteins are distinct and may perform diverse functions. Some VgrG proteins have been found to carry C-terminal extensions, which carry conserved domains of various predicted functions. The N-terminal of these "evolved VgrGs" may serve in assembly of the T6SS machinery, while the C-terminal portion functions as effector [16]. One such evolved VgrG in $V$. cholerae (VgrG-1) carries an actin-binding domain in its $\mathrm{C}$-terminal extension which has been shown to be involved in host cell toxicity [20]. The C-terminal extension of a VgrG in S. enterica subsp. arizonae (IIIa) carries an S-type pyocin domain which has been proposed to function in bacterial cell killing [14]. Over $500 \mathrm{VgrG}$ orthologs have been identified in bacterial genome sequences with many of these representing evolved VgrGs. In a number of organisms for which genome sequences are available, additional Hcp and VgrG paralogs with a function in T6SS, termed "orphan" Hcps and VgrGs are encoded by genes located on the genome separately from the T6SS loci [14,21].

The genera Pantoea and Erwinia include ecologically diverse species, including the plant pathogens Erwinia amylovora and Pantoea stewartii subsp. stewartii, which are linked to devastating diseases of rosaceous plants and maize, respectively [22,23]. The opportunistic plant pathogen Pantoea ananatis causes disease on a broad range of host plants and has been associated with human bacteremia [24]. Several Erwinia species, including Erwinia billingiae and Erwinia tasmaniensis, are found as part of the normal epiphytic microflora of plants [25]. Strains of Pantoea agglomerans and Pantoea vagans have recently received attention as potent biological control agents [26-28]. Strains of both Pantoea and Erwinia have also been isolated from insects [29,30]. The complete and draft genomes of several Pantoea and Erwinia species have recently been sequenced, which provide an extensive base to identify genomic differences that may be linked to the divergent biological and ecological phenotypes of these species. We used the genome sequences to identify the T6SS in these organisms. An in depth analysis was undertaken which showed that not all T6SS loci are universal to the sequenced Pantoea and Erwinia species and that there are notable anomalies between some of the loci that are conserved among the compared organisms. We show that these differences occur in putative genomic islands associated with the Hcp and VgrG proteins and postulate that these islands represent regions of rapid and extensive evolution, which may drive functional diversification of the T6SS. 


\section{Results and Discussion \\ Several orthologous T6SS loci occur in Pantoea and Erwinia species}

By means of baiting with the conserved proteins from several characterized T6SS in other bacteria, between two and four T6SS loci were identified in the complete or draft genome sequences of five Pantoea and four Erwinia strains (Figure 1). These strains were the Eucalyptus pathogen P. ananatis LMG 20103 [31], the biological control strains $P$. vagans C9-1 [32] and $P$. agglomerans E325 (Smits and Duffy, unpublished results), the insect-associated strains Pantoea sp. aBvalens [29] and Pantoea sp. At-9b [30] which represent novel species of the genus Pantoea, the fire blight pathogens E. amylovora CFBP 1430 [22] and E. pyrifoliae DSM $12163^{\mathrm{T}}$ [33] and the apple epiphytes E. tasmaniensis Et1/99 [34] and E. billingiae Eb661 [25]. Two orthologous loci are found in all Pantoea and Erwinia strains, while a more restricted distribution could be observed for the T6SS-3 locus (Figure 1). Additional T6SS loci were identified in the genome sequences of $E$. billingiae Eb661 and Pantoea sp. aB-valens, respectively.

The T6SS-1 loci range in size from 28.8 and $40.0 \mathrm{~kb}$ and are built around a well-conserved and syntenous core which includes orthologs of all sixteen conserved T6SS proteins identified by Boyer et al. [15] (Figure 2 and 3). Additional genes encode a serine/threonine protein kinase (PpkA) and serine/threonine phosphatase (PppA). These proteins interact with the Fork Head-Associated (FHA) domain protein (COG3456) for the post-translational regulation of the T6SS [35]. In both Pantoea and Erwinia strains the conserved core T6SS proteins are arranged in two syntenous clusters (block I and III - Figure 2 and 3). These are separated by a variable region (block II), which is linked to the $h c p$ gene (COG3157). A further variable region occurs next to the $\operatorname{vgrG}$ gene (block IV). In all sequenced Pantoea and Erwinia genomes, with the exception of E. pyrifoliae DSM $12163^{\mathrm{T}}$, this variable region is flanked at the 3' end by a gene encoding a re-arrangement hot spot (rhs) element [36]. In P. agglomerans E325, E. amylovora CFBP 1430, E. pyrifoliae DSM $12163^{\mathrm{T}}$ and E. tasmaniensis Et1/99, an additional copy of the $\operatorname{vgrG}$ gene occurs within this variable region. A non-conserved region harboring two hypothetical genes, which is not associated with a $\operatorname{vgr}$ or $h c p$ gene could be observed between COG3520 and clpV in E. tasmaniensis Et1/99 and E. pyrifoliae DSM $12163^{\mathrm{T}}$ (Figure 3).

The T6SS-2 loci of the Pantoea strains and E. billingiae Eb661 are structurally and genetically conserved and consist of eight syntenous genes which encode proteins that are highly conserved among the sequenced strains (Figure 4). Only four of these belong to conserved T6SS proteins outlined by Boyer et al. [15], suggesting the T6SS-2 loci encodes a partial and potentially non-functional T6SS. An average amino acid identity of $52 \%$ could be observed between the proteins encoded in the T6SS-2 locus and their respective paralogs in the T6SS-1 locus for each of the strains. This suggests that the T6SS-2 locus could have arisen through a partial duplication of the T6SS-1 locus. This is supported by phylogenetic analysis with the IcmF (COG3523) protein sequences (Figure 5), where the T6SS-2 loci branch

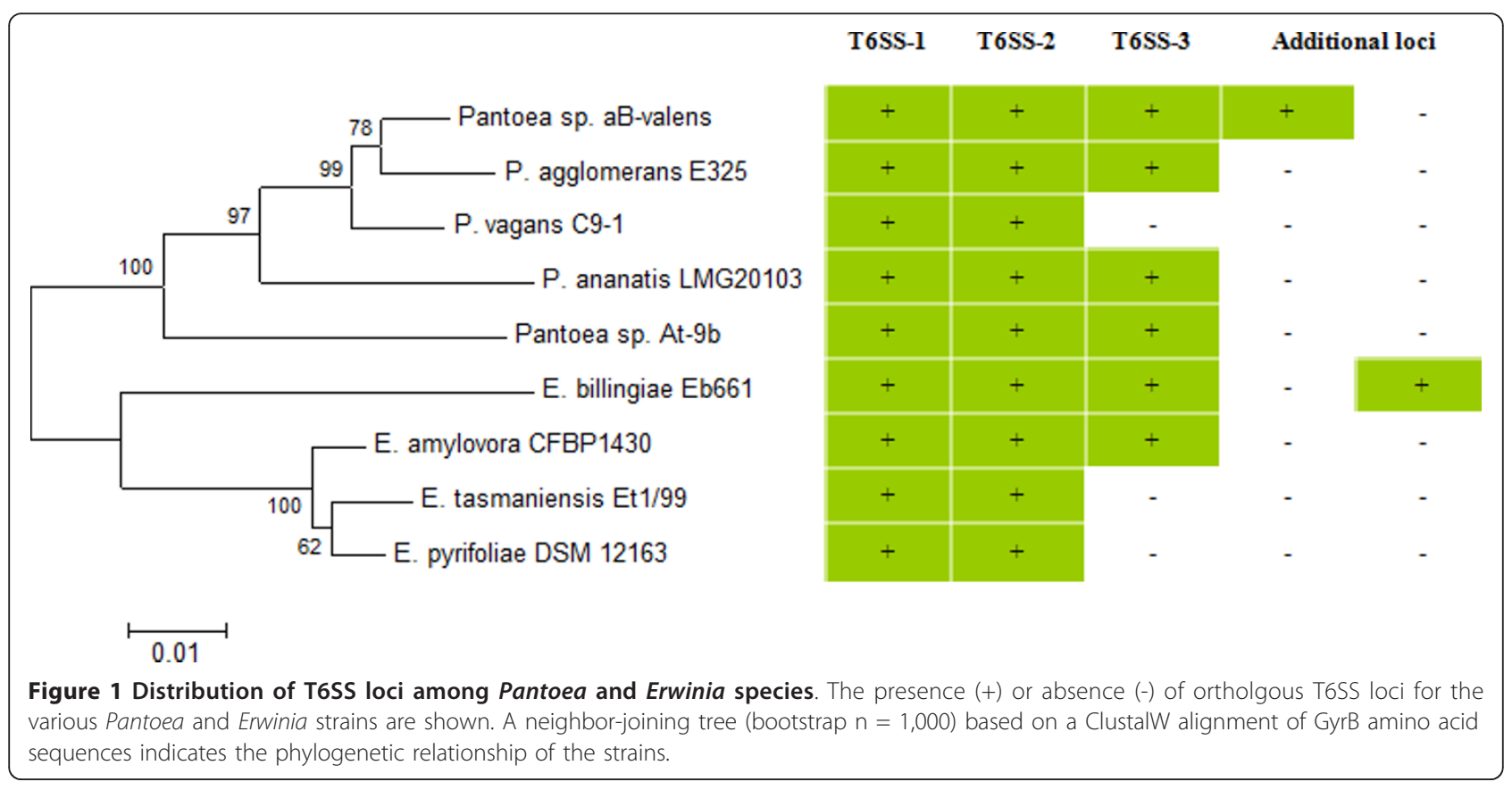




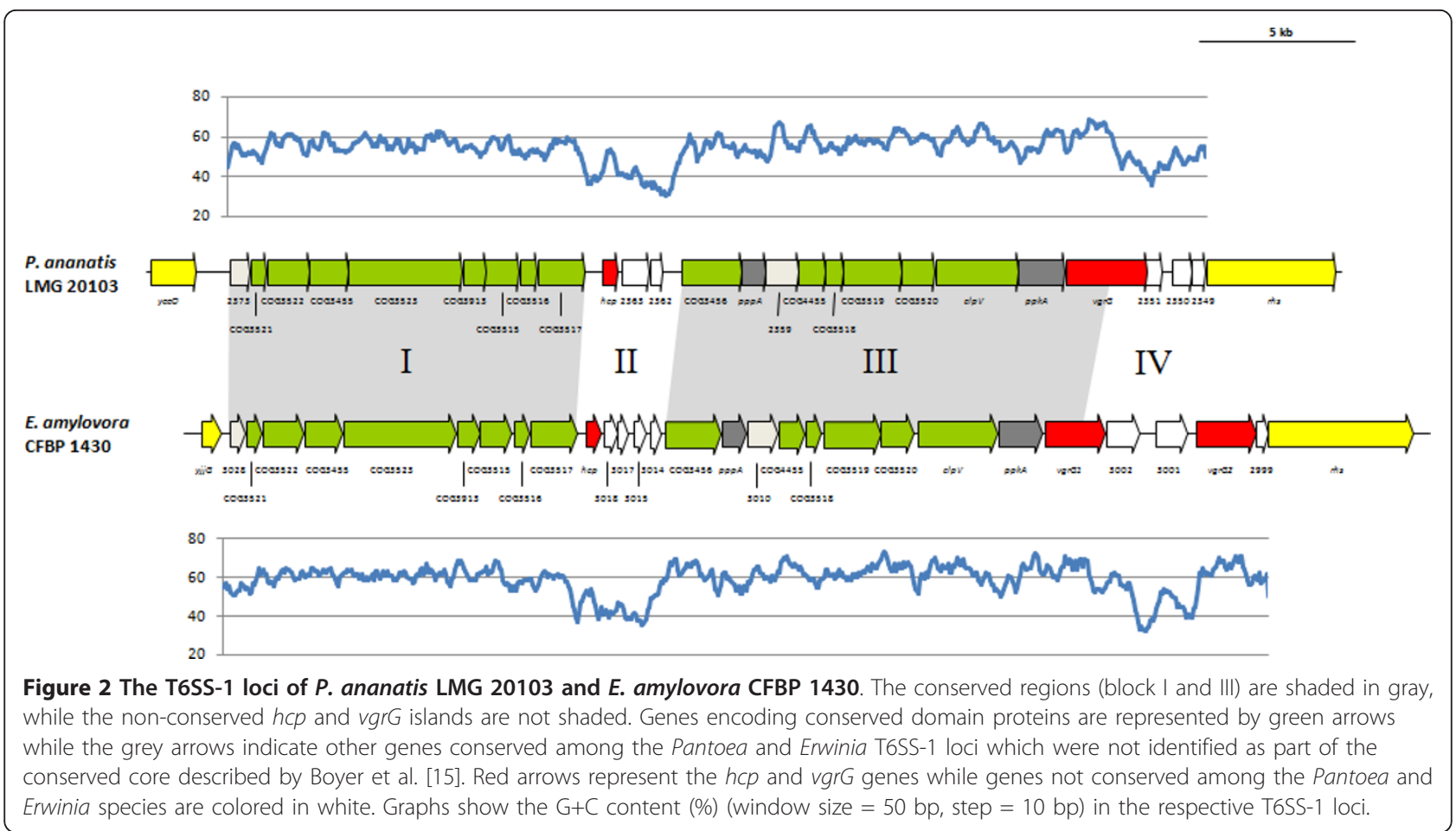

from the T6SS-1 loci. The E. amylovora CFBP 1430 and E. pyrifoliae DSM $12613^{\mathrm{T}}$ T6SS-2 loci encode only four proteins, lacking the genes encoding the serine/threonine kinase and phosphatase required for posttranslational regulation, while an FHA domain (COG3456) protein is encoded in these loci. The $i c m F$ gene in the E. pyrifoliae DSM12613 ${ }^{\mathrm{T}}$ T6SS-2 locus is inactivated by a frameshift [33], while the E. tasmaniensis Et1/99 T6SS-2 locus is missing the FHA domain gene, indicating further gene loss in these T6SS loci (Figure 4).

The Pantoea and Erwinia T6SS-3 loci are between 18.8 and $34.6 \mathrm{~kb}$ in size and encompass 19 to 32 protein coding sequences. In contrast to the T6SS-1 and -2 loci, the T6SS-3 locus is not universal to all Pantoea and Erwinia strains (Figure 1). The phylogeny based on the IcmF protein shows a greater evolutionary distance between the Pantoea and Erwinia T6SS-3 loci, which are interspersed with those of other Enterobacteriaceae (Figure 5), indicating that this locus may have been acquired through horizontal gene transfer. This can also be correlated with greater diversity in gene content and order between the various Pantoea and Erwinia T6SS-3 loci (Figure 6 and 7). Thirteen of the T6SS conserved core proteins identified by Boyer et al. [15] are encoded within the T6SS loci. Genes encoding orthologs of the COG3913, COG4455 and FHA domain (COG3456) proteins are absent. No PpkA or PppA orthologs are encoded in the T6SS-3 loci either, suggesting that this locus is not post-translationally regulated. As in the case of the T6SS-1 loci, syntenous blocks of core genes can be observed in the T6SS-3 loci (block I, III and V - Figure 6 and 7). Here, the $h c p$ gene is included in a conserved block (Figure 6 and 7). The non-conserved regions in the T6SS-3 loci are generally associated with a $\operatorname{vgr} G$ gene. An additional complete and two partial $v g r G$ genes can be found in the T6SS-3 locus of E. amylovora CFBP 1430. An additional non-conserved region, encoding two predicted proteins, PANA_4135 and PANA_4136 can be observed in the P. ananatis LMG 20103 T6SS-3 locus (Figure 7).

A further T6SS locus was identified in Pantoea sp. aBvalens (Figure 8). This $19.6 \mathrm{~kb}$ locus encodes thirteen conserved core proteins. The IcmF phylogeny shows this T6SS locus to be distantly related to all other Pantoea and Erwinia T6SS loci. Similarly, an additional partial T6SS locus is encoded on the E. billingiae Eb661 genome, which contains four T6SS core proteins. A nonconserved region associated with the $\operatorname{vgrG}$ gene is likewise present. This E. billingiae Eb661 T6SS locus is flanked at both the 5' (EbC_39320 - phage integrase) and 3' end (EbC_393430-39600 - hypothetical phage genes) by genes of an integrated phage element. A phage origin has previously been hypothesized for the T6SS [17].

Different VgrG proteins are encoded in the T6SS-1, T6SS3 loci and additional T6SS loci

The amino acid sequences of all VgrG proteins encoded in the T6SS-1, T6SS-3 and additional T6SS loci in E. 


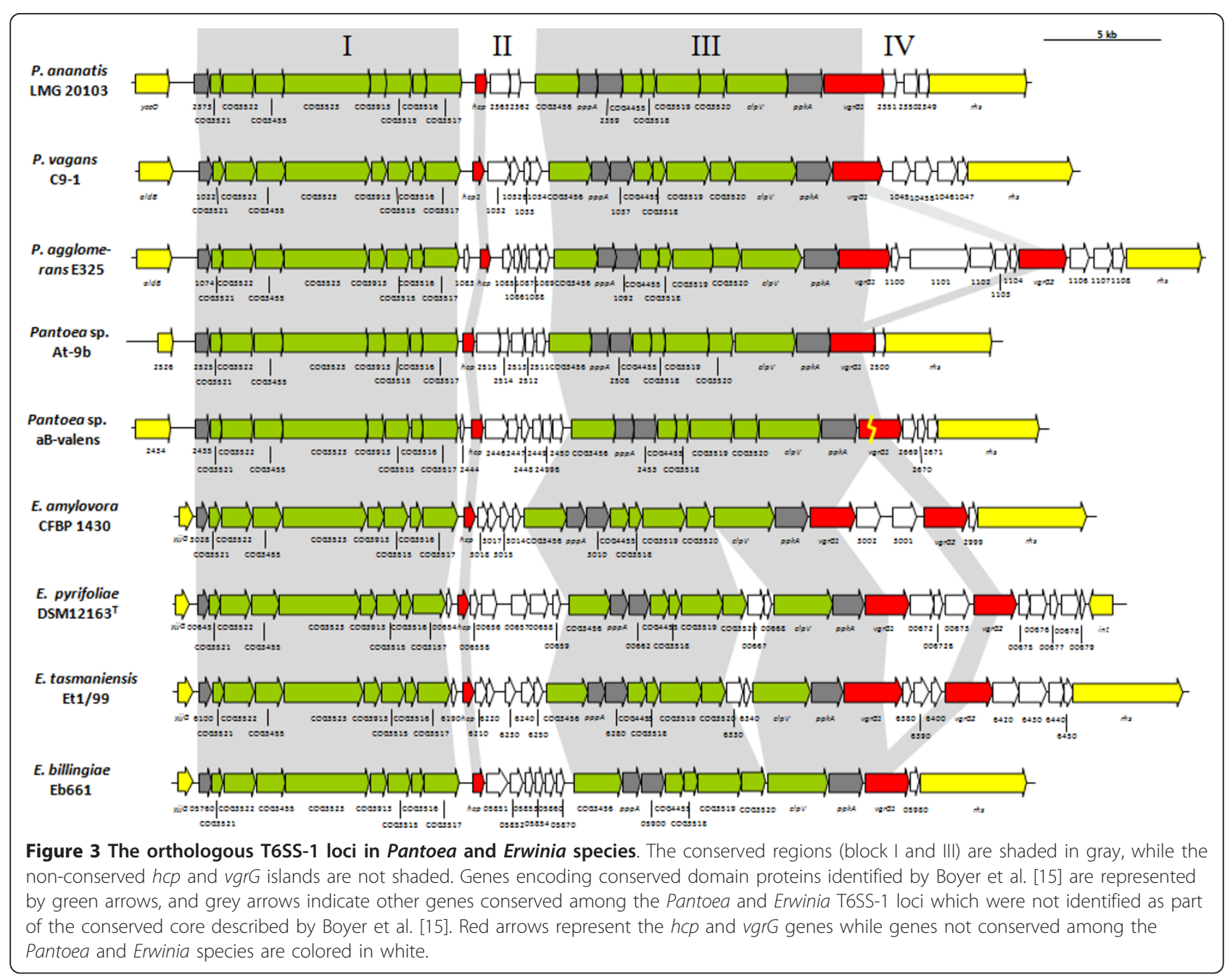

billingiae and Pantoea sp. aB-valens were analyzed for the presence of conserved and evolved domains. The $\mathrm{N}$ terminal region of all T6SS-1, T6SS-3 and additional T6SS VgrG proteins is conserved among all Pantoea and Erwinia species and contains a conserved VgrG (TIGR3361 [37]) and phage Gp5 (pfam04717 [38]) domain (Figure 9). However, as has been observed in other bacteria, the VgrG proteins differ considerably in length between the various Pantoea and Erwinia species. This can be attributed to variable C-terminal regions, which suggest that they represent evolved VgrG proteins. Seven of the thirteen Pantoea and Erwinia T6SS-1 VgrG proteins contain such C-terminal extensions (Figure 10). Analysis of these C-terminal extensions showed that several of them contain conserved domains. The $P$. agglomerans E325 T6SS-1 VgrG2 protein (Pagg_1105) contains a peptidoglycan (PG)-binding domain (Pfam09374 [38] - Cdsearch score: 45) as well as COG3926 and COG5526 lysozyme domains $[39,40]$, which were also found in the lytic bacteriophage $\phi 8$, suggesting a bacteriolytic function for this VgrG protein. A similar function can be expected for the Pantoea sp. aB-valens T6SS-1 VgrG (PANABDRAFT_2668) which contains a $\beta$-N-acetyl-glucosaminidase domain (COG4193 [40] - Cdsearch score: 58.5) in its C-terminal extension. The E. tasmaniensis Et1/99 T6SS-1 VgrG2 (ETA_06370) C-terminal extension shows structural homology to the Streptomyces sp. N174 chitosanase (1_chk_A - Hhpred score: 190) [41].

The C-terminal extensions of VgrG proteins encoded in the T6SS-3 loci of all Pantoea and Erwinia species contain a conserved domain of unknown function (COG4253), which is absent in the T6SS-1 loci VgrG proteins (Figure 9). This domain has also been identified flanking the N-terminal region of the S. enterica subsp. arizonae IIIa VgrG proteins, while it is not present in the VgrG proteins of other Salmonella serovars [14]. A role for the COG4253 domain, which links the N-terminal VgrG transporter and C-terminal extension, in modulating the function of the $\mathrm{VgrG}$ between secretion 


\section{P. ananatis \\ LMG 20103 \\ P. vagans \\ C9-1}

\section{P. agglomerans}

E325

Pantoea sp.

At-9b

\section{Pantoea sp. aB-valens}

\section{E. billingiae Eb661}

\section{E. amylovora CFBP 1430}

\section{E. pyrifoliae DSM12163 ${ }^{\top}$}

\section{E. tasmaniensis Et1/99}
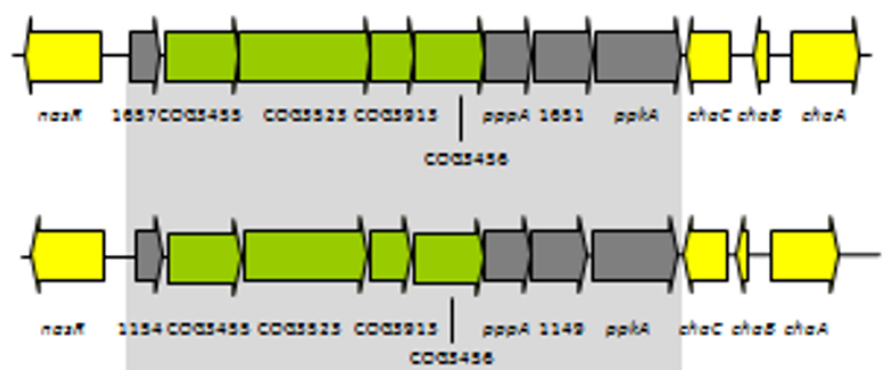

$$
\text { codsuse }
$$

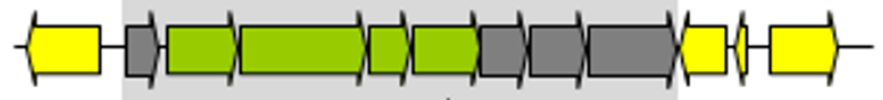

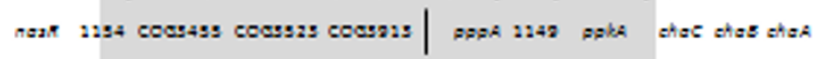

$\cos 45$

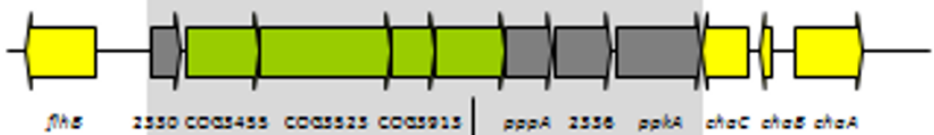

$\cos 450$

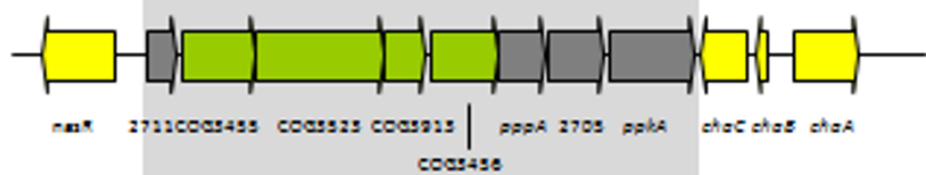

cocsuse

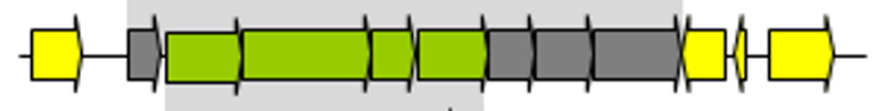

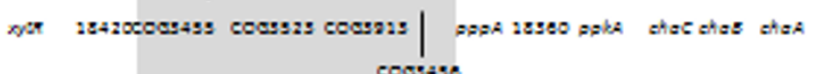
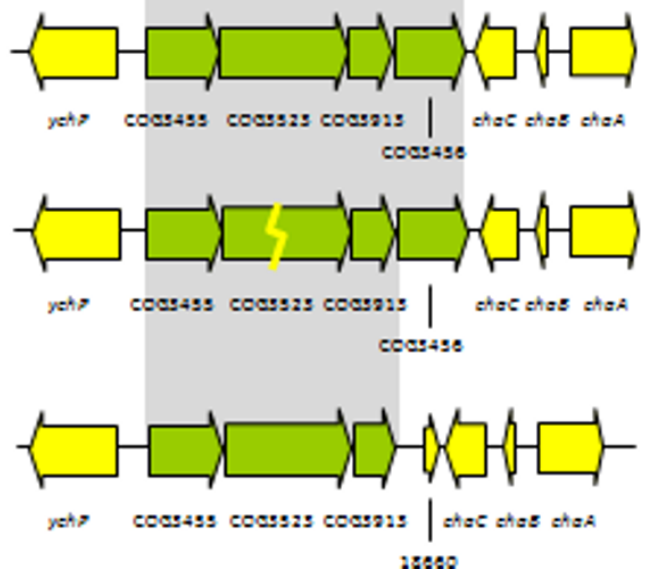

Figure 4 The orthologous T6SS-2 loci in Pantoea and Erwinia species. Genes encoding proteins with the conserved domains identified by Boyer et al. [15] are represented by green arrows while the grey arrows indicate other genes conserved among the Pantoea and Erwinia T6SS-2 loci which were not identified as part of the conserved core. White arrows represent the genes not conserved among the Pantoea and Erwinia species. 


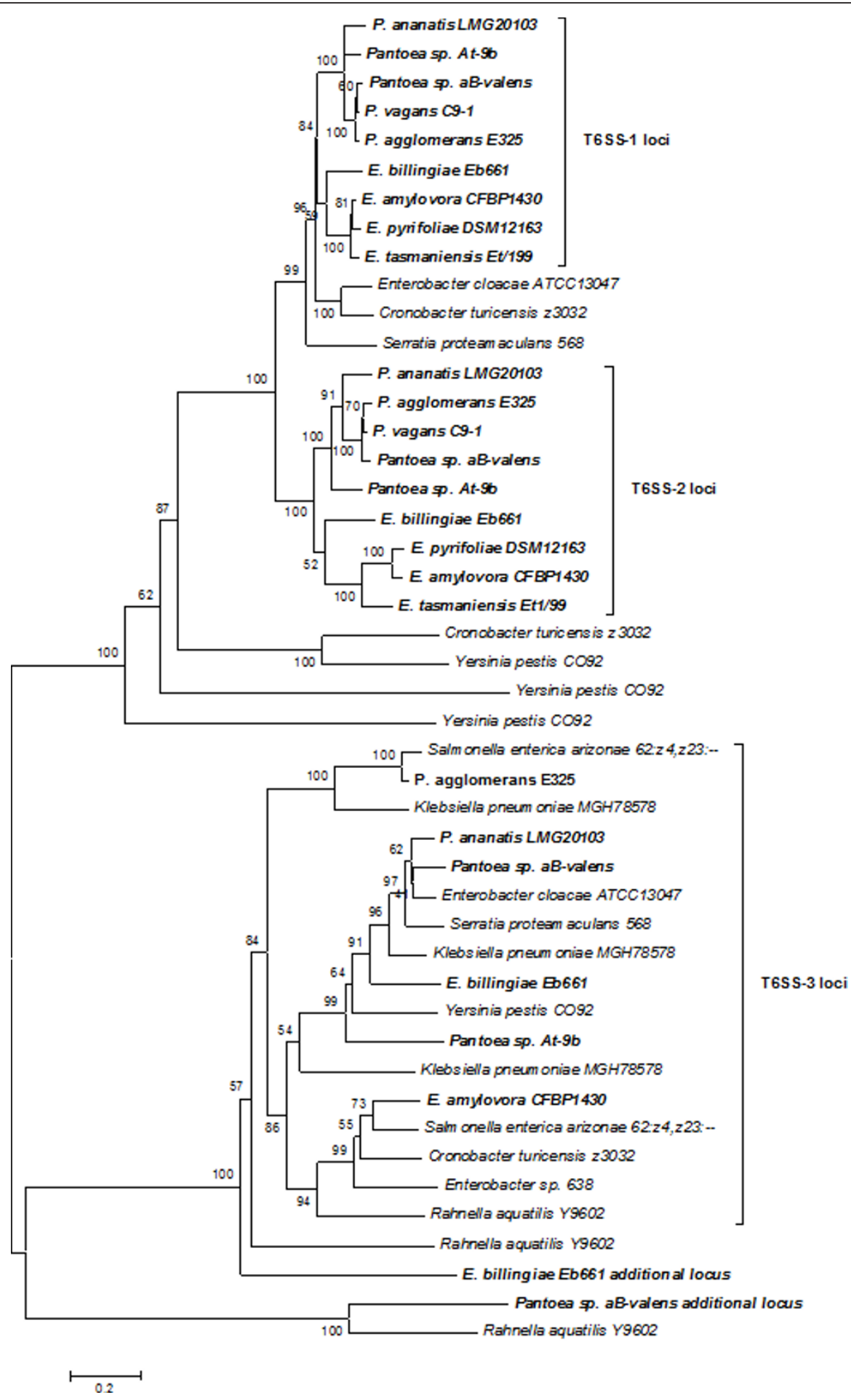

Figure 5 Phylogenetic relationships between the T6SS loci among the Pantoea and Erwinia species. A neighbor-joining tree (bootstrap $n$ = 1,000; Poisson correction; Complete gap deletion) was constructed based on a ClustalW alignment of the IcmF (COG3523) amino acid sequences from the Pantoea and Erwinia T6SS loci and orthologous loci in several closely related Enterobacteriaceae. 

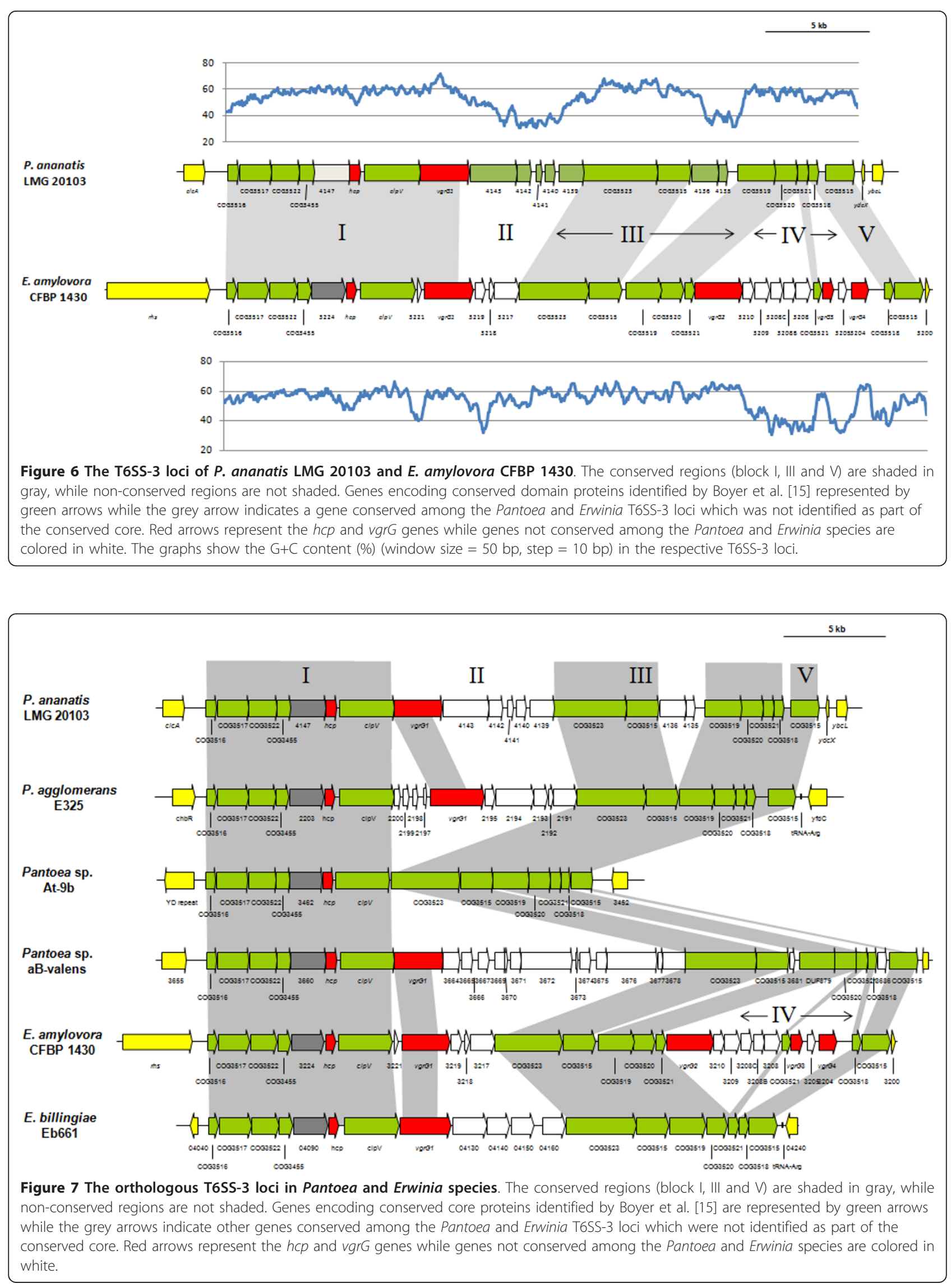
Pantoea sp. aB

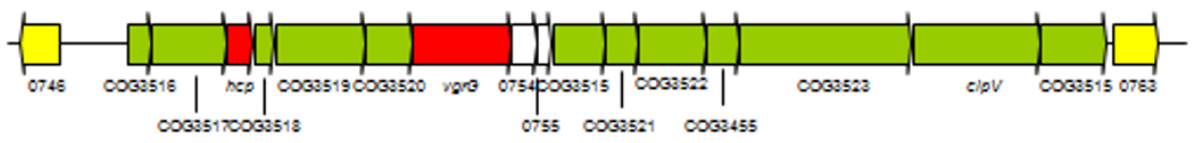

\section{E. billingiae Eb661}

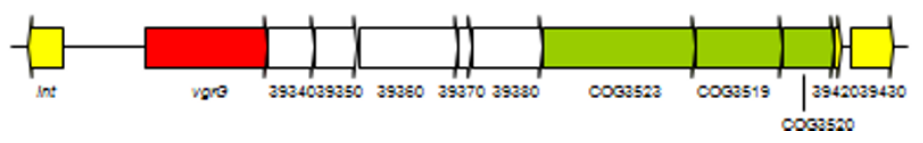

Figure 8 Additional T6SS loci in Pantoea sp. aB-valens and Erwinia billingiae Eb661. Genes encoding proteins with the conserved domains identified by Boyer et al. [15] are indicated by green arrows. Red arrows represent the hcp and vgrG genes while genes not conserved among the Pantoea and Erwinia species are colored in white.

and virulence has been suggested [15]. However, with the exception of the P. agglomerans E325 T6SS-3 VgrG protein, which carries a $\mathrm{C}$-terminal extension subsequent to the COG4253 region, no further $\mathrm{C}$-terminal extensions are present in the Pantoea and Erwinia
T6SS-3 VgrG proteins. An alternative function in host cell adhesion has also been suggested [16]. The latter function would imply that the COG4253-positive T6SS3 and COG4253-negative T6SS-1 VgrG proteins could have different targets and serve different functions. A

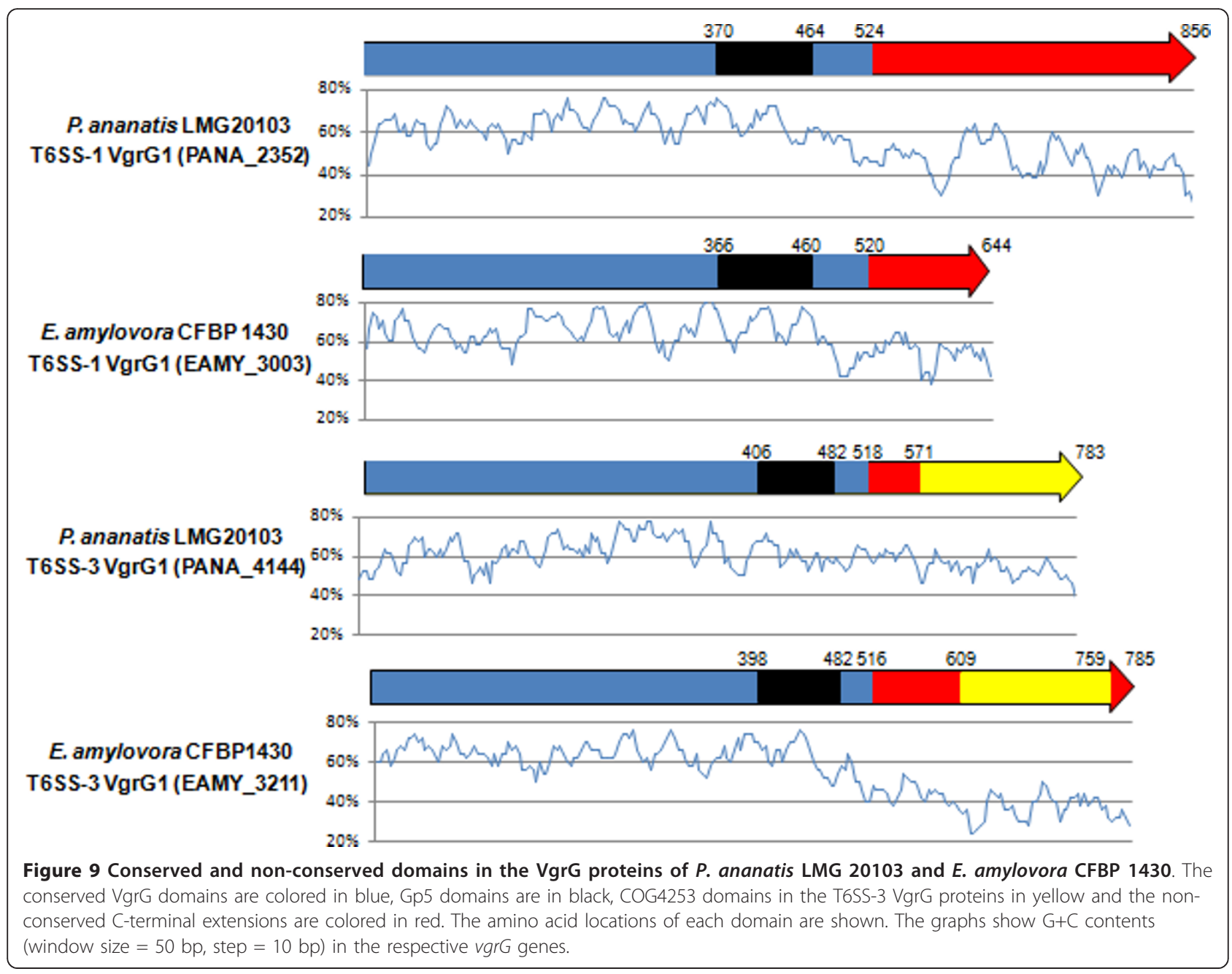




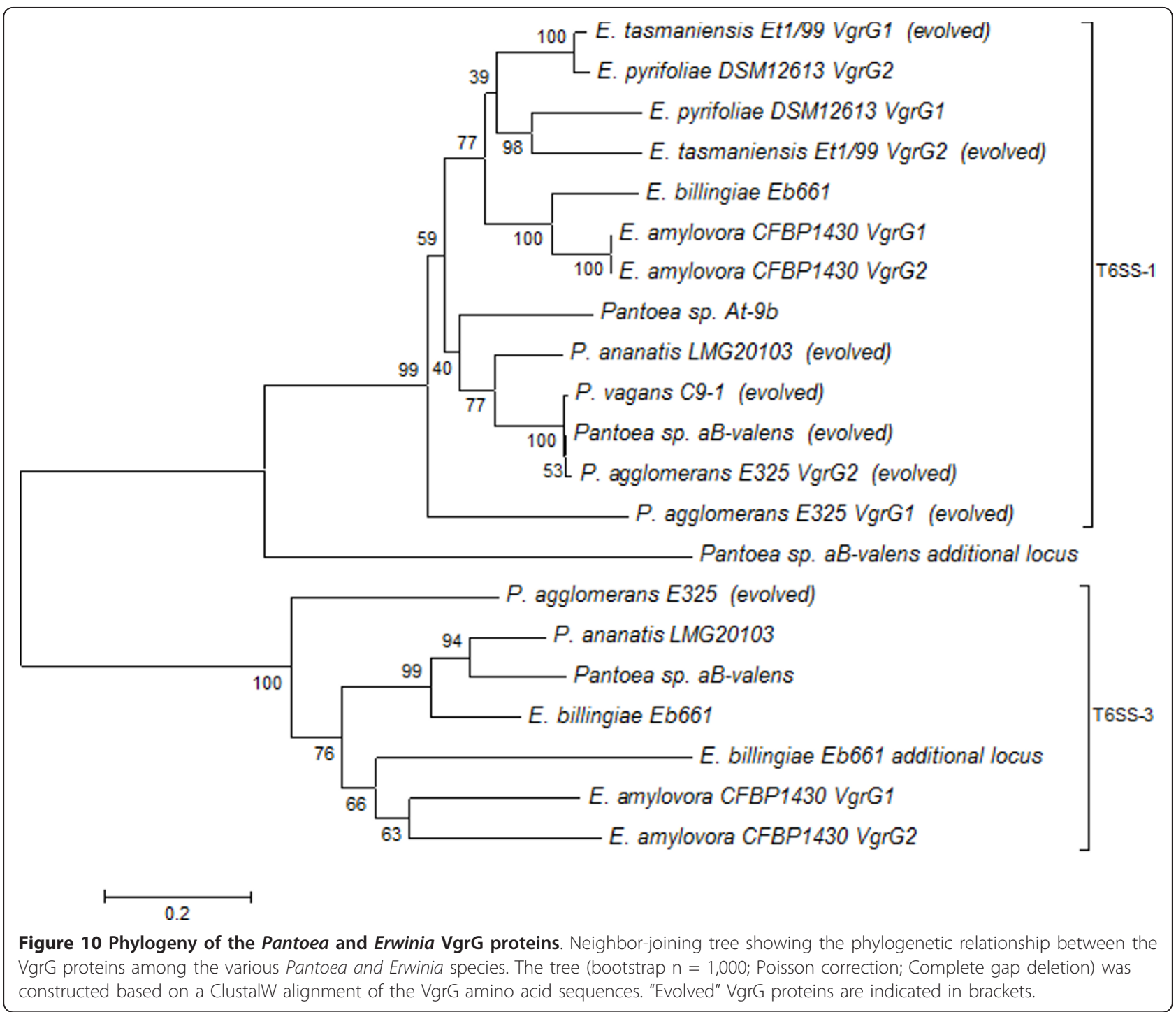

phylogeny based on the T6SS-1 and T6SS-3 VgrG proteins shows that they branch into two distinct clades suggesting distinct evolutionary backgrounds for these paralogous proteins (Figure 10). The VgrG protein found in the additional T6SS locus in E. billingiae Eb661 also contains a conserved COG4253 domain and clusters with the T6SS-3 VgrG proteins, while the additional Pantoea sp. aB-valens VgrG paralog clusters with the other VgrG proteins lacking this domain.

\section{Non-conserved $h c p / v g r G$ regions represent islands within the T6SS loci}

While the T6SS-1 and T6SS-3 loci share conserved and syntenous cores among the various Pantoea and Erwinia strains, considerable variability in the $v g r G$ and $h c p$ regions can be observed. The $\mathrm{G}+\mathrm{C}$ deviation across these T6SS loci was determined. This showed that for the T6SS-1 and
T6SS-3 loci, there is a much lower $\mathrm{G}+\mathrm{C}$ content in the variable regions associated with the $h c p$ and $\operatorname{vgrG}$ genes compared to the conserved core regions (Figures 2 and 4). In the T6SS-1 loci, the conserved core regions had an average $\mathrm{G}+\mathrm{C}$ content of $60.17 \%$ across all strains, while the $h c p$ regions (average $\mathrm{G}+\mathrm{C} \%=42.30$ ) and $v g r G$ regions (average $\mathrm{G}+\mathrm{C} \%=47.91$ ) had a much lower $\mathrm{G}+\mathrm{C}$ content. The substantial $\mathrm{G}+\mathrm{C}$ deviations, variability in the gene content of the $h c p$ and $v g r G$ regions and the differential homology of proteins encoded in these regions to proteins in bacteria in other genera indicates that these regions represent variable islands within the T6SS loci. Similar G $+C$ deviations could be observed for the $\operatorname{vgr} G$ regions in the additional Pantoea sp. aB-valens and E. billingiae Eb661 T6SS loci, which further supports that these regions serve as "hot spots" for rearrangement [36]. These hot spots are frequently associated with Rhs proteins which 
are capable of displacing its C-terminal tip and replacing it with a non-homologous alternative. By this means, the Rhs protein can drive the sequential insertion of heterogeneous C-terminal sequences into the hot spot [36]. As the additional E. billingiae Eb661 T6SS locus occurs within an integrated phage element, we postulate that transducing phages may play a role in the horizontal acquisition of non-conserved genes in the $v g r G$ and $h c p$ regions. Similar $v g r G / h c p$ islands have also been identified in a number of Pseudomonas species [42]. These islands are associated with "orphan" $v g r G$ and $h c p$ paralogs separately located from the remainder of the T6SS loci. In contrast, this is the first observation of $h c p$ and $v g r G$ islands associated with the conserved core T6SS loci. Analysis of the T6SS loci of other bacteria (data not shown), however, shows that this phenomenon is not restricted to Pantoea and Erwinia.

\section{Hcp/VgrG islands harbor putative effector proteins}

The proteins encoded in the variable $h c p$ and $v g r G$ islands in the T6SS-1 and T6SS-3 loci in the different Pantoea and Erwinia species were analyzed for sequence similarity and structural homology to known proteins and the presence of conserved domains. The majority of proteins encoded on the islands showed homology to proteins of unknown function. However, a number of island proteins share high sequence identity and contain conserved domains which suggest they may represent T6SS effectors with putative functions in host-microbe and inter-bacterial interactions (Additional File 1 Table S1).

The amino acid sequence of ETA_06430 encoded in the E. tasmaniensis Et1/99 T6SS-1 vgrG island shares homology with a phospholipase in $V$. cholerae HE48 (VCHE48_2681 - 40\% aa identity) while that of E. billingiae Eb661 EbC_4130 encoded on the T6SS-3 vgrG island shows homology to a lipase/esterase in Yersinia bercovieri ATCC 43970 (Yberc0001_35290 -64\% aa identity). The former also shows structural homology to a $P$. aeruginosa lipase (1ex9_A - Hhpred score: 115) while the latter shows structural homology to a lipase in Penicillium expansum (3g7n_A: Hhpred score: 157), supporting that these two proteins represent lipases. Similarly, EbC_39360 encoded in the additional T6SS of E. billingiae Eb661 shares weak structural homology with a lipase in Archaeoglobus fulgidus (2zyr_A - Hhpred score: 81.1). Lipases hydrolyze long-chain triglycerides into fatty acids and glycerol and have been shown to represent major virulence factor in both animal and plant pathogens [43,44]. Genes encoding lipases were also identified in the $\operatorname{vgrG}$ islands of $P$. aeruginosa and transcriptome analysis showed that their expression is co-regulated with that of the T6SS [42]. These lipases may therefore represent T6SS-secreted effectors in $P$. aeruginosa as well as the Erwinia species. Several genes in the $\operatorname{vgrG}$ regions of both Pantoea and Erwinia
T6SS-1 and T6SS-3 loci may encode proteases. The $P$. agglomerans E325 Pagg2200 and E. tasmaniensis Et1/99 ETA_6240 proteins share $28 \%$ and $32 \%$ aa identity respectively with a putative zinc protease in Acinetobacter baumanii (AbauB_010100012633) and show weak structural homology to a zinc metalloproteases in Geobacter sulfurreducens (3c37_A - Hhpred score: 47.3 and 51.3, respectively). Furthermore, the P. agglomerans E325 Pagg_1085, E. tasmaniensis Et1/99 ETA_6210 and E. amylovora CFBP 1430 EAMY_3018 protein sequences show weak structural homology to the secreted cysteine protease stathopain (1cv8_A - Hhpred score: 29.834 .2 and 34.2, respectively), which plays a role in skin infection by Staphylococcus aureus [45]. EbC_39340 and EbC_39350 localized in the vgrG island in the additional T6SS locus of E. billingiae Eb661 encode proteins with weak structural homology to the secreted Clostridium perfringens sialidase NanI (2bf6_A Hhpred score: 46 and 44.3, respectively) which is involved in the removal of sialic acids from host glycoconjugates with an important role in bacterial nutrition and pathogenesis [46]. PANA_4143 associated with the T6SS-3 in P. ananatis LMG 20103, shares high sequence homology with the M23 peptidase of Klebsiella sp. 92-3 (HMPREF9538_05689: 78\% aa identity) and extensive structural homology to the secreted chitinase G of Streptomyces coelicolor of (1chk_A - Hhpred score: 203). Chitinases degrade chitin, the carbohydrate polymer found in insect shells and the cell walls of fungi, suggesting the T6SS of P. ananatis LMG 20103 may secrete an effector with an antifungal or insecticidal function [47].

Two proteins, PANA_2363 and Pagg_2194, encoded in the T6SS-1 and T6SS-3 hcp islands of P. ananatis LMG20103 and P. agglomerans E325, respectively contain conserved peptidoglycan binding (Pfam01474 PG_binding_1) and LysM (Pfam01476) domains which are typically associated with proteins involved in bacterial cell wall degradation. The latter also shows sequence homology to a putative lytic enzyme in Acinetobacter calcoaceticus RUH2202 (HMPREF0012_02474 - 34\% aa identity). Similarly, E. pyrifoliae DSM $12163^{\mathrm{T}}$ Epyr_0675 shares sequence homology with a Edwardsiella tarda FL6-60 lysozyme (ETAF_ple052 - 32\% aa identity) and also contains a conserved peptidoglycan binding domain (Pfam09374 - PG_binding_3) and a domain of unknown function (DUF847) frequently observed in lysozymes. The E. billingiae Eb661 EbC_05851 protein also shares sequence homology with the Pseudomonas phage PaP1 endolysin (PaP1_gp072 - 46\% aa identity). The presence of domains conserved in bacterial cell wall degrading enzymes and the sequence homology to these enzymes indicate that these proteins may play a similar role to the Tse 1 and Tse 3 lytic enzymes in P. aeruginosa in the degradation of the bacterial cell wall and may thus have a bactericidal function $[12,48]$. Furthermore, 
PANA_4136 encoded in the additional non-conserved region in the $P$. ananatis LMG 20103 T6SS-3 locus shows extensive sequence homology to S-pyocin domain containing proteins in E. coli 3030-1 (EC30301_3278 $58 \%$ aa identity) and Yersinia pseudotuberculosis IP 31758 (YpsIP31758_0897 - 53\% aa identity) and shows weak structural homology to the colicin S4 of Escherichia coli (3few_X - Hhpred score: 45.5). Similarly, weak structural homology to colicin S4 can be observed for the T6SS hcp island P. vagans C9-1 Pvag_1032, Pantoea sp. At-9b Pat9b_2515 and Pantoea sp. aB-valens PANABDRAFT_2446 proteins (3few_X - Hhpred score: $60,58.5$ and 58.4, respectively). Colicins and pyocins are bacteriocins that are involved in killing closely related bacterial species [49]. The presence of bacteriocin-like proteins in the T6SS loci of these Pantoea species agrees with the finding of a potential function for the T6SS in antibiosis and competition $[11,12]$.

\section{Pantoea and Erwinia VgrG and Hcp proteins may carry effector proteins encoded in the vgrG and $h c p$ islands} Analysis of the $\mathrm{G}+\mathrm{C}$ contents of the Pantoea and Erwinia T6SS-1 vgrG genes shows that the N-terminal regions, which contain the conserved VgrG and Gp5 domains, have an average $\mathrm{G}+\mathrm{C}$ content of $63.68 \%$, which is similar to the conserved core of the T6SS-1 loci. By contrast, the $\mathrm{C}$-terminal extensions have an average $\mathrm{G}+\mathrm{C}$ content of $46.59 \%$. This is similar to the non-conserved $v g r G$ island, suggesting that the $\mathrm{C}$-terminal extensions form part of the $\operatorname{vgrG}$ islands. In the T6SS-3 loci, the conserved Nterminal region of the $\operatorname{vgr} G$ genes has an average $\mathrm{G}+\mathrm{C}$ content of $59.01 \%$ while the $\operatorname{vgrG}$ islands have an average $\mathrm{G}+\mathrm{C}$ content of $48.38 \%$.

Some of the proteins encoded in the $v g r G$ islands show sequence homology and contain conserved domains found in the C-terminal extensions of evolved VgrG proteins. The E. pyrifoliae DSM $12163^{\mathrm{T}}$ T6SS-1 Epyr_00675 amino acid sequence shares $75 \%$ aa identity with the C-terminal region of the P. agglomerans E325 T6SS-1 evolved VgrG (Pagg_1105). The P. ananatis LMG 20103 T6SS-1 PANA_2363 and the C-terminal region of the evolved T6SS-1 VgrG of P. agglomerans E325 (Pagg_1105) also each contain a PG-binding domain and a LysM domain (Pfam01476) found in lytic enzymes, and show structural homology a cell wall degrading lysozyme in Pseudomonas phage Phikz (2kbh_A - Hhpred score: 128 and 44.5, respectively). BlastP analysis with the proteins encoded in the $\operatorname{vgrG}$ islands against the NCBI protein database showed that proteins encoded in the $v g r G$ islands of several Pantoea and Erwinia species show substantial sequence identity to the C-terminal extensions in VgrG in bacteria belonging to other genera (Additional File 1 Table $\mathrm{S} 1)$. The putative lytic enzymes encoded in the T6SS-1 vgrG islands of P. ananatis LMG 20103 (PANA_2363) and
E. billingiae Eb661 (EbC_05851) share homology with the C-terminal extensions in the VgrG proteins of $V$. cholerae TMA21 (VCB_002278 - 41\% aa identity) and V. cholerae CT 5369-63 (VIH_000452 - 49\% aa identity), respectively. The putative zinc proteases encoded in the $P$. agglomerans E325 T6SS-3 vgrG island (Ppag_2200) and the E. tasmaniensis Et1/99 T6SS-1 vgrG island (ETA_06240) share 43 and $46 \%$ aa identity with the C-terminal extension of a Burkholderia sp. 383 VgrG protein (Bcep18194_C7612). Similarly, the putative E. tasmaniensis Et1/99 lipase (ETA_06430) shows $42 \%$ aa identity to the Burkholderia glumae BGR1 VgrG (Bglu_2g02560). The sequence homology and the presence of shared conserved domains between the C-terminal extensions of evolved VgrG proteins and putative effector proteins encoded in the $v g r G$ islands, suggest that VgrG proteins may carry effector proteins encoded in the vgrG islands. The COG4253 conserved domain found at the C-terminal end of all the T6SS-3 VgrG proteins may be involved in the anchorage of the VgrG transporter to the effector proteins, thereby modulating the function of the VgrG protein as a structural component of the T6SS apparatus and the transport of effector proteins [15]. This domain is absent in the T6SS-1 loci, and the means by which effectors become associated with the VgrG transport region would need to be determined.

In the fish pathogen Edwardsiella tarda, the secreted effector protein EvpP has been shown to interact with the Hcp protein [50]. Furthermore, Hcp orthologs with C-terminal extensions have been identified in S. enterica, which may represent evolved Hcp proteins [14]. It is therefore plausible that, as is the case for the Pantoea and Erwinia VgrG proteins, the Hcp proteins may transport effector proteins encoded on the $h c p$ islands. By this means, various effector proteins could be tagged to the VgrG and Hcp proteins, thereby forming different VgrGeffector and Hcp-effector combinations, which may perform different biological functions. The VgrG or Hcp proteins could transport bacteriocins or pyocins, which would allow the bacterium to target other bacteria competing for an ecological niche. A chitinase effector carried by the VgrG protein could play an antifungal or insecticidal role in the Pantoea and Erwinia species. These and other putative pathogenicity factors encoded by hypothetical proteins in the $h c p$ and $v g r G$ islands translocated by the VgrG and Hcp proteins may therefore enable Pantoea and Erwinia species to target a range of bacterial, invertebrate, vertebrate and or plant hosts.

\section{Conclusions}

Comparative analysis of the genome sequences of several Pantoea and Erwinia species revealed that they encode between two and four T6SS loci. This suggests an important biological role for this secretion system in these two 
genera. Two of the T6SS loci, T6SS-1 and T6SS-2 are shared among all Pantoea and Erwinia strains, while orthologs of the third locus are only found in four of five Pantoea species and two of four Erwinia species, suggesting acquisition by horizontal gene transfer of this locus. Pantoea sp. aB-valens and E. billingiae Eb661 encode additional T6SS loci. Analysis of the T6SS-1, T6SS-3 and additional loci in Pantoea sp. aB-valens and E. billingiae Eb661 showed that while synteny is conserved among the Pantoea and Erwinia species for each locus, non-conserved regions could be observed associated with the $h c p$ and $\operatorname{vgrG}$ genes. The $\mathrm{G}+\mathrm{C}$ contents of these non-conserved regions differ substantially from the conserved portions of the loci, indicating horizontal acquisition of these regions separate from the rest of the T6SS loci. Several of the VgrG proteins encoded in the loci have a Cterminal extension and represent evolved VgrG proteins. These C-terminal extensions likewise have lower $\mathrm{G}+\mathrm{C}$ contents than the remainder of the T6SS suggesting they form part of the $\operatorname{vgrG}$ islands.

Many of the proteins encoded in the $\operatorname{vgr} G$ and $h c p$ islands carry conserved domains and show sequence and structural homology to proteins with various biological functions including antibiosis, fungal cell wall degradation and putative roles in animal and plant pathogenesis. We postulate that the $\operatorname{vgrG}$ and $h c p$ islands may represent evolutionary hot spots for genes that encode effector proteins. Similar rearrangement hot spots have been observed in the regions adjacent to the $h c p$ and $\operatorname{vgrG}$ genes in the T6SS loci of other bacteria $[18,36]$, suggesting that this is a more widespread phenomenon. The sequence similarity and structural homology of some of these putative effector proteins to C-terminal extensions in characterized evolved VgrG proteins suggest that they may become tagged to the conserved core VgrG proteins which serve as transporters for these effectors, thereby forming new evolved VgrG proteins. Similarly, putative effectors encoded in the $h c p$ islands may become associated with the Hcp proteins to form evolved Hcp proteins. We could therefore speak of "evolving" Hcp and VgrG proteins. By tagging various effector proteins different VgrG-effector and Hcp-effector combinations could be formed which may perform different biological functions. Thereby, the genomic islands associated with the Hcp and VgrG proteins could drive functional diversification of the T6SS, which may explain the plethora of biological roles described for this secretion system.

\section{Methods}

In silico identification of the T6SS loci in Pantoea and Erwinia

The T6SS loci in five Pantoea and four Erwinia species, for which complete or draft genome sequences are available, were identified: Pantoea ananatis LMG 20103 [31], Pantoea vagans C9-1 [32], Pantoea agglomerans E325 (Smits and Duffy, unpublished results), Pantoea sp. aB-valens [29], Pantoea sp. At-9b [30], Erwinia amylovora CFBP 1430 [22], Erwinia pyrifoliae DSM $12163^{\mathrm{T}}$ [33], Erwinia tasmaniensis Et1/99 [35] and Erwinia billingiae Eb661 [25]. Identification of the T6SS loci was done by BlastP analysis [51] with the conserved core proteins identified by Boyer et al. [15] against local protein databases created for the Pantoea and Erwinia strains. Proteins neighboring Pantoea and Erwinia T6SS clusters were compared using BlastP against the NCBI protein database [52] to identify to full extent of the T6SS loci. Sequence manipulations were conducted with multiple subroutines of the LASERGENE package (DNASTAR, Madison, WI, USA).

\section{Phylogenetic analyses}

Phylogenetic analyses were done using the procedures outlined by Bingle et al. [53]. A ClustalW alignment with default parameters was performed with the IcmF (COG3523) amino acid sequences, as this represents the only protein conserved among all Pantoea and Erwinia T6SS loci. A phylogenetic tree was constructed with the Molecular Evolutionary Genetics Analysis (MEGA) v. 5.0.3 software package [54], using the neighbor-joining method, with Poisson correction, complete gap deletion and bootstrapping $(\mathrm{n}=1,000)$ parameters. The IcmF amino acid sequences from the T6SS loci of several closely related organisms as identified by BlastP analysis against the NCBI protein database [52] were included in the tree. This same procedure was employed to construct phylogenetic trees for Gyrase B (GyrB) and the VgrG proteins.

\section{Analyses of the hcp/vgrG islands}

The average $\mathrm{G}+\mathrm{C}$ contents for the conserved core regions and $h c p$ and $v g r G$ islands of the T6SS loci were determined using the Bioedit v.7.0.5.3 package [55]. The $\mathrm{G}+\mathrm{C}$ content was determined using $50 \mathrm{bp}$ windows in $10 \mathrm{bp}$ steps. Similarly, the $\mathrm{G}+\mathrm{C}$ contents for the $\operatorname{vgrG}$ genes were determined for the conserved $\mathrm{N}$-terminal region, which included the conserved Vgr and Gp5 domains, and for the C-terminal extension which was considered as all nucleotides located at the 3 ' end of the Gp5 domain. Proteins encoded in the $v g r G$ and $h c p$ islands were identified using the FgenesB [56] and Orf finder [57] web servers. The amino acid sequences for the proteins encoded in the $h c p$ and $v g r G$ islands were analyzed for sequence identity by BlastP analysis against the NCBI protein database $[51,52]$ the presence of conserved domains by Blast analysis against the Conserved Domain Database (CDsearch) [58,59]. Structural homology of the $v g r G$ and $h c p$ island proteins to those for 
which the chemical structure has been determined was performed using the HHpred server (http://toolkit.tuebingen.mpg.de/hhpred) [60,61].

\section{Conflicting interests}

The authors declare that they have no competing interests.

\section{Additional material}

Additional file 1: Table S1 Non-conserved proteins encoded in the T6SS hcp and vgrG islands in Pantoea and Erwinia species. Table showing the Blast analysis of the proteins encoded in the Pantoea and Erwinia hcp and vgrG islands against the NCBI protein database [52], Conserved Domain Database using the CD-search server [58] and the Protein Database (PDB) using the Hhpred server [60,61]. For the BlastP analysis against the NCBI protein database, the highest informative Blast result outside of the Pantoea/Erwinia group was determined. The amino acid positions showing sequence identity, percentage amino acid (aa) identity, bit scores and BLAST E-values are shown. For the Blast analysis for conserved domains [58], the protein families and conserved orthologous groups are shown, as well as the bit scores and E-values. For the Hhpred analysis of the amino acid sequences for structural homology the Hhpred scores and E-values are shown.

\section{Acknowledgements}

This study was partially supported by the National Research Foundation (NRF), the Tree Protection Co-operative Programme (TPCP), the NRF/Dept. of Science and Technology Centre of Excellence in Tree Health Biotechnology (CTHB), and the THRIP support program of the Department of Trade and Industry, South Africa, the Swiss Federal Office for Agriculture (BLW Fire Blight Research - Pathogen), and the Swiss Secretariat for Education and Research (SBF C07.0038). It was conducted within the European Science Foundation funded research network COST Action 864 and the Swiss ProfiCrops program. We acknowledge Cameron Currie, Aaron Adams and the JGl for the use of the Pantoea sp. aB-valens genome.

\section{Author details}

${ }^{1}$ Forestry and Agricultural Biotechnology Institute, University of Pretoria, South Africa. ${ }^{2}$ Agroscope Changins-Wädenswil ACW, Division of Plant Protection, Wädenswil, Switzerland.

\section{Authors' contributions}

PDM, SNV, BD, TAC and THMS conceived the study. PDM, TK and THMS performed experiments and analysis. PDM, SNV, BD, TAC, and THMS wrote the original manuscript. All authors read and approved the final version.

Received: 8 August 2011 Accepted: 24 November 2011 Published: 24 November 2011

\section{References}

1. Mougous JD, Cuff ME, Raunser S, Shen A, Zhou M, Giford CA, Goodman AL, Joachimiak G, Ordoñez CL, Lory S, Walz T, Joachimiak A, Mekalanos JJ: A virulence locus of Pseudomonas aeruginosa encodes a protein secretion apparatus. Science 2006, 312:1526-1530.

2. Pukatzki S, Sturtevant D, Krastins B, Sarracino D, Nelson WC, Heidelberg JF, Mekalanos JJ: Identification of a conserved bacterial protein secretion system in Vibrio cholerae using the Dictyostelium host model system. Proc Natl Acad Sci USA 2006, 103:1528-1533.

3. Jani AJ, Cotter PA: Type VI Secretion: Not just for pathogenesis anymore. Cell Host Microbe 2010, 8:2-6.

4. Schwarz S, Hood RD, Mougous JD: What is type VI secretion doing in all those bugs? Trends Microbiol 2010, 18:531-537.

5. Aschtgen M-S, Thomas MS, Cascales E: Anchoring the type VI secretion system to the peptidoglycan. Virulence 2010, 1:535-540.
6. Parsons DA, Heffron F: sciS, an icmF homolog in Salmonella enterica serovar Typhimurium limits intracellular replication and decreases virulence. Infect Immun 2005, 73:4338-4345.

7. Chow J, Mazmanian SK: A pathobiont of the microbiota balances host colonization and intestinal inflammation. Cell Host Microbe 2010, 7:265-276

8. Liu H, Coulthurst SJ, Pritchard L, Hedley PE, Ravensdale M, Burr T, Takle G, Brurberg M-B, Birch PRJ, Salmond GPC, Toth IK: Quorum sensing coordinates brute force and stealth modes of infection in the plant pathogen Pectobacterium atrosepticum. PLOS Path 2008, 4:e1000093.

9. Robinson JB, Telepnev MV, Zudina IV, Bouyer D, Montenieri JA, Bearden SW, Gage KL, Agaer SL, Foltz SM, Chauhan S, Chopra AK, Motin VL: Evaluation of a Yersinia pestis mutants impaired in a thermoregulated type VI-like secretion system in flea, macrophage and murine models. Microb Pathog 2009, 47:243-251.

10. Bladergroen MR, Badelt K, Spaink HP: Infection-blocking genes of a symbiotic Rhizobium leguminosarum strain that are involved in temperature-dependent protein secretion. Mol Plant-Microbe Interact 2003, 16:53-64.

11. Hood RD, Singh $P$, Hsu F, Carl MA, Trinidad RRS, Silverman JM, Ohlson BB, Hicks KG, Plemel RL, Li M, Schwarz S, Wang WY, Merz AJ, Goodlett DR, Mougous JD: A type $\mathrm{VI}$ secretion system of Pseudomonas aeruginosa targets a toxin to bacteria. Microbe 2010, 7:25-37.

12. Russell AB, Hood RD, Bui NK, LeRoux M, Vollmer W, Mougous JD: Type VI secretion delivers bacteriolytic effectors to target cells. Nature 2011, 475:343-347

13. MacIntyre DL, Miyata ST, Kitaoka M, Pukatzki SL: The Vibrio cholerae type VI secretion system displays antimicrobial properties. Proc Natl Acad Sci USA 2011, 9:6-10

14. Blondel CJ, Jiménez JC, Contreras I, Santiviago CA: Comparative genomic analysis uncovers 3 novel loci encoding type six secretion systems differentially distributed in Salmonella serotypes. BMC Genomics 2009, 10:1-17.

15. Boyer F, Fichant G, Berthod J, Vandenbrouck Y, Attree I: Dissecting the bacterial type VI secretion system by a genome wide in silico analysis: what can be learned from available microbial genomic resources? BMC Genomics 2009, 10:104-11.

16. Pukatzki S, Revel AT, Sturtevant D, Mekalanos JJ: Type VI secretion system translocates a phage tail spike-like protein into target cells where it cross-links actin. Proc Natl Acad Sci USA 2007, 104:15508-15513.

17. Leiman PG, Basler M, Ramagopal UA, Bonanno JB, Sauder JM, Pukatzki S, Burley SK, Almo SC, Mekalanos JJ: Type VI secretion apparatus and phage tail-associated protein complexes share a common evolutionary origin. Proc Natl Acad Sci USA 2009, 106:4154-4159.

18. Pukatzki S, McAuley SB, Miyata ST: The type VI secretion system: translocation of effectors and effector-domains. Curr Opin Microbiol 2009, 12:11-17.

19. Hachani A, Lossi NS, Hamilton A, Jones C, Bleves S, Albesa-Jové D, Filloux A: Type VI secretion system in Pseudomonas aeruginosa: secretion and multimerization of VgrG proteins. J Biol Chem 2011, 286:12317-12327.

20. Ma AT, McAuley S, Pukatzki S, Mekalanos JJ: Translocation of a Vibrio cholerae type VI secretion effector requires bacterial endocytosis by host cells. Cell Host Microbe 2009, 5:234-243.

21. Sarris PF, Skandalis N, Kokkinidis M, Panopoulos NJ: In silico analysis reveals multiple putative type $\mathrm{VI}$ secretion systems and effector proteins in Pseudomonas syringae pathovars. Mol Plant Pathol 2010, 11:795-804.

22. Smits THM, Rezzonico F, Kamber T, Blom J, Goesmann A, Frey JE, Duffy B: Complete genome sequence of the fire blight pathogen Erwinia amylovora CFBP 1430 and comparison to other Erwinia spp. BMC Genomics 2010, 23:384-393.

23. Braun EJ: Ultrastructural investigation of resistant and susceptible maize inbreds infected with Erwinia stewartii. Phytopathology 1982, 72:159-166.

24. Coutinho TA, Venter SN: Pantoea ananatis: an unconventional plant pathogen. Mol Plant Pathol 2009, 10:325-335.

25. Kube M, Migdoll AM, Gehring I, Heitmann K, Mayer Y, Kuhl H, Knaust F, Geider K, Reinhardt R: Genome comparison of the epiphytic bacteria Erwinia billingiae and $E$. tasmaniensis with the pear pathogen $E$. pyrifoliae. BMC Genomics 2010, 11:393.

26. Pusey PL, Stockwell VO, Rudell DR: Antibiosis and acidification by Pantoea agglomerans strain E325 may contribute to suppression of Erwinia amylovora. Phytopathology 2008, 98:1136-1143. 
27. Stockwell VO, Johnson KB, Sugar D, Loper JE: Control of fire blight by Pseudomonas fluorescens A506 and Pantoea vagans C9-1 applied as single strains and mixed inocula. Phytopathology 2010, 100:1330-1339.

28. Smits THM, Rezzonico F, Kamber T, Goesmann A, Ishimaru CA, Frey JE, Stockwell VO, Duffy B: Metabolic versatility and antibacterial metabolite biosynthesis are distinguishing genomic features of the fire blight antagonist Pantoea vagans C9-1. PLoS One 2011, 6:e22247.

29. Adams AS, Currie CR, Cardoza Y, Klepzig KD, Raffa KF: Effects of symbiotic bacteria and tree chemistry on the growth and reproduction of bark beetle fungal symbionts. Can J For Res 2009, 39:1133-1147.

30. Pinto-Tomás AA, Anderson MA, Suen G, Stevenson DM, Chu FST, Cleland WW, Weimer PJ, Currie CR: Symbiotic nitrogen fixation in the fungus gardens of leaf-cutter ants. Science 2009, 326:1120-1123.

31. De Maayer P, Chan WY, Venter SN, Toth IK, Birch PRJ, Joubert F, Coutinho TA: Genome sequence of Pantoea ananatis LMG 20103, the causative agent of Eucalyptus blight and dieback. J Bacteriol 2010, 192:2936-2937.

32. Smits THM, Rezzonico F, Kamber T, Goesmann A, Ishimaru CA, Stockwell VO, Frey JE, Duffy B: Genome sequence of the biocontrol agent Pantoea vagans C9-1. J Bacteriol 2010, 192:6486-6487.

33. Smits THM, Jaenicke S, Rezzonico F, Kamber T, Goesmann A, Frey JE, Duffy B: Complete genome sequence of the fire blight pathogen Erwinia pyrifoliae DSM $12163^{\top}$ and comparative genomic insights into plant pathogenicity. BMC Genomics 2010, 4:2

34. Kube M, Migdoll AM, Müller I, Kuhl H, Beck A, Reinhardt R, Geider K: The genome of Erwinia tasmaniensis strain Et1/99, a non-pathogenic bacterium in the genus Erwinia. Environ Microbiol 2008, 10:2211-2222.

35. Mougous JD, Gifford CA, Ramsdell TL, Mekalanos JJ: Threonine phosphorylation post-translationally regulates protein secretion in Pseudomonas aeruginosa. Nature Cell Biol 2007, 9:797-803.

36. Jackson AP, Thomas GH, Parkhill J, Thomson NR: Evolutionary diversification of an ancient gene family (rhs) through C-terminal displacement. BMC Genomics 2009, 16:1-16.

37. TIGRFAM database. [http://www.jcvi.org/cgi-bin/tigrfams/].

38. Protein families (PFAM) database. [http://pfam.sanger.ac.uk]

39. Pei J, Grishin NV: COG3926 and COG5526: A tale of two new lysozymelike protein families. Prot Sci 2005, 14:2574-2581.

40. Conserved Orthologous Groups database. [http://www.ncbi.n/m.nih.gov/ COG/grace/].

41. Protein Databank (PDB). [http://www.pdb.org/].

42. Barret M, Egan F, Fargier E, Morrisey JP, O'Gara F: Genomic analysis of the type VI secretion systems in Pseudomonas spp: novel clusters and putative effectors uncovered. Microbiology 2011, 157:1726-1739.

43. Nardini M, Lang DA, Liebeton K, Jaeger K-E, Dijstra BW: Crystal structure of Pseudomonas aeruginosa lipase in the open conformation. $J$ Biol Chem 2000, 275:31219-31225.

44. Ham JH, Melanson RA, Rush MC: Burkholderia glumae: next major pathogen of rice? Mol Plant Pathol 2011, 12:329-339.

45. Filipek R, Rzychon M, Olesky A, Gruca M, Dubin A, Potempa J, Botchler M: The staphostatin-staphopain complex: a forward binding inhibitor in complex with its target cysteine protease. J Biol Chem 2003, 278:40959-40966.

46. Newstead SL, Potter JA, Wilson JC, Xu G, Chien C-H, Watts AG, Withers SG, Taylor GL: The structure of Clostridium perfringens Nanl sialidase and its catalytic intermediates. J Biol Chem 2008, 283:9080-9088.

47. Hoell IA, Dalhus B, Heggset EB, Aspmo SI, Eijsink VGH: Crystal structure and enzymatic properties of a bacterial family 19 chitinase reveal differences from plant enzymes. FEBS J 2006, 273:4889-4900.

48. Fokine A, Miroshnikov KA, Shneider MM, Mesyanzhinov W, Rossmann MG: Structure of the bacteriophage $\varphi \mathrm{KZ}$ lytic transglycosylase gp144. J Biol Chem 2008, 11:7247-7250.

49. Michel-Briand $Y$, Baysse $C$ : The pyocins of Pseudomonas aeruginosa. Biochimie 2002, 84:499-510.

50. Zheng J, Leung KY: Dissection of a type VI secretion system in Edwardsiella tarda. Mol Microbiol 2007, 66:1192-1206.

51. Altschul SF, Gish W, Miller W, Myers EW, Lipman DJ: Basic local alignment search tool. J Mol Biol 1990, 215:403-410.

52. National Centre for Biotechnology Information protein database. [http:// www.ncbi.nlm.nih.gov/blast].

53. Bingle LEH, Bailey CM, Pallen MJ: Type VI secretion: a beginner's guide. Curr Opin Microbiol 2009, 11:3-8.
54. Kumar S, Dudley J, Nei M, Tamura K: MEGA: a biologist-centric software for evolutionary analysis of DNA and protein sequences. Brief Bioinform 2008, 9:299-306.

55. Hall TA: BioEdit: a user-friendly biological sequence alignment editor and analysis program for Windows 95/98/NT. Nucl Acids Symp Ser 1999, 41:95-98.

56. Softberry FgenesB bacterial operon and gene prediction server. [http:// linux1.softberry.com].

57. National Centre for Biotechnology Information open reading frame prediction server. [http://www.ncbi.nlm.nih.gov/gorf/].

58. Marchler-Bauer A, Bryant SH: CD-Search: protein domain annotations on the fly. Nucleic Acids Res 2004, 32:327-331.

59. National Centre for Biotechnology Information conserved protein domain search server. [http://www.ncbi.nlm.nih.gov/Structure/cdd/wrpsb.cgi].

60. Söding J, Biegert A, Lupas AN: The HHpred interactive server for protein homology detection and structure prediction. Nucleic Acids Res 2005, , 33: W244-248.

61. Homology detection and structure prediction by HMM-HMM comparison server. [http://toolkit.tuebingen.mpg.de/hhpred].

doi:10.1186/1471-2164-12-576

Cite this article as: De Maayer et al:: Comparative genomics of the type VI secretion systems of Pantoea and Erwinia species reveals the presence of putative effector islands that may be translocated by the VgrG and Hcp proteins. BMC Genomics 2011 12:576.

\section{Submit your next manuscript to BioMed Central and take full advantage of:}

- Convenient online submission

- Thorough peer review

- No space constraints or color figure charges

- Immediate publication on acceptance

- Inclusion in PubMed, CAS, Scopus and Google Scholar

- Research which is freely available for redistribution

Submit your manuscript at www.biomedcentral.com/submit
C Biomed Central 